\title{
Factors influencing local attitudes and perceptions regarding jaguars Panthera onca and National Park conservation in Panama
}

\author{
Jessica L. Fort, Clayton K. Nielsen, Andrew D. Carver \\ Ricardo Moreno and Ninon F. V. Meyer
}

\begin{abstract}
Throughout its range in Latin America the jaguar Panthera onca is threatened by habitat loss and fragmentation, and conflict with humans. Protected areas in Panama harbour some of the last remaining suitable habitat for jaguars and are vital to conservation. However, no previous studies had assessed which factors in particular affect the tolerance of rural Panamanians towards jaguars and National Park conservation, which is important to jaguar persistence. Whether these factors are consistent with previous research on human-carnivore coexistence is unclear. To address this we estimated the number of instances of depredation of cattle by jaguars, and assessed attitudes and perceptions of rural Panamanians. We conducted semistructured interviews in two disparate study areas: Cerro Hoya National Park and Darién National Park. Depredation events were more frequent in the latter, but only residents of the former reported conflict between people and coyotes Canis latrans. Positive perceptions of jaguars and National Parks, and criticism of park management, increased with level of education and land ownership. Men were more open to receiving help on their farms to mitigate impacts of jaguars, and more tolerant of the presence of jaguars, than women. Residents from both study areas indicated high appreciation for their respective National Parks. We provide recommendations to improve community outreach and education initiatives, and suggest priority areas for future mitigation efforts concerning human-jaguar interactions in Panama.
\end{abstract}

Keywords Cerro Hoya National Park, Darién National Park, human-wildlife interaction, jaguar, Panama, stakeholders, surveys

Supplementary material for this article can be found online at https://doi.org/10.1017/So030605317001016

Jessica L. Fort (Corresponding author), Clayton K. Nielsen, Andrew D. Carver* Department of Forestry and Cooperative Wildlife Laboratory, Southern Illinois University, Carbondale, IL, USA. E-mail jessicafort85@gmail.com

Ricardo Morenoł and Ninon F. V. Meyerł Fundación Yaguará Panamá, Sociedad Panameña de Biología, San Francisco, Panama

*Also at: Asociación Panamericana para la Conservación, Gamboa Resort, Colón, Panama

†Also at: Smithsonian Tropical Research Institute, Balboa, Ancón, Panama

$\ddagger$ Also at: El Colegio de la Frontera Sur, Department of Biodiversity

Conservation, Ciudad Industrial, Lerma, Campeche, Mexico

Received 21 November 2016. Revision requested 9 March 2017.

Accepted 9 June 2017. First published online 17 October 2017.

\section{Introduction}

Atitudes are defined as favourable or unfavourable dis$A_{\text {positions towards an action (Dickman et al., 2013), and }}$ perceptions refer to how we interpret our surroundings and thus provide meaning to our environment (Bowditch et al., 2007), both of which are the sum of many factors and ultimately affect people's tolerance of wildlife. Assessing public attitudes and perceptions helps acquire knowledge about issues related to human-wildlife coexistence, and should be used to establish long-term conservation strategies for large carnivores (Conforti \& Azevedo, 2003; Davenport et al., 2010). Attitudes of stakeholder groups are especially important to consider, as they can significantly affect policy, thus making the foundations of carnivore management as social and political as they are scientific (Smith et al., 2014). In areas where human-related mortality is a threat to carnivore populations, identifying which socio-economic factors influence attitudes and perceptions is critical in targeting appropriate resolutions to negative human-wildlife interactions, whether they involve community-based education initiatives, rancher outreach, or improvement of policies.

Hostility towards carnivores or, conversely, the appreciation of and receptivity to their conservation, can be determined by individual-level factors such as age, gender, wealth and education, or by societal- and cultural-level factors such as collective experiences, social norms, and folklore and religion (Dickman et al., 2013). In Brazil, perceptions of jaguars were found to differ between riverside communities, where negative perceptions were related to concern for people's safety, and ranching and rural communities, where negative perceptions were related to economic losses associated with jaguar attacks on cattle (Porfirio et al., 2016). In addition, younger respondents with a higher level of education tended to have more positive perceptions of jaguars. Although respondents viewed jaguars as being dangerous, they did not support the eradication of jaguars in their natural habitat, which the authors attributed to the anthropocentric value of protecting jaguars for future generations (Porfirio et al., 2016). Case studies such as this illustrate the complexities of human-carnivore coexistence, such that relationships between communities and predators are not always obvious or predictable; for example, negative perceptions of jaguars do not always translate into their killing (Delibes-Mateos, 2014), and likewise, positive 
perceptions of jaguars are not always synonymous with their protection.

In Panama, cattle ranches bordering National Parks facilitate contact between cattle and large carnivores, specifically jaguars (Moreno et al., 2016). Throughout their range, jaguar populations are threatened by human-caused habitat loss, depletion of prey, and retaliatory killing in response to livestock predation (de la Torre et al., 2017). During 1989-2014 a minimum of 230 jaguars were killed by people in Panama, with 96\% killed in retaliation for livestock predation (Moreno et al., 2015). There have been several reports of predation issues and retaliatory killings of jaguars on ranches near the Panama Canal (Moreno \& Olmos, 2008; Carrión de Samudio \& Samudio, 2012; Brossard \& Pritz, 2013). Jaguars are categorized as Endangered in Panama (MINAM, 2016; de la Torre et al., 2017), with a potentially Critically Endangered subpopulation in Cerro Hoya National Park in the Azuero Peninsula (Fort et al., 2014; Moreno et al., 2015, 2016; Fort, 2016). As human activity is the main threat to jaguars, it is important to understand how people perceive and interact with this species, and to what degree they value the protected areas critical to its survival. However, aside from the surveys mentioned above, no studies have assessed how demographic and socio-economic factors in particular affect tolerance of jaguars and the conservation of National Parks among rural Panamanians.

Our objective was to measure local attitudes and perceptions as an indicator of tolerance towards jaguars and National Park conservation in Cerro Hoya National Park and an area bordering Darién National Park. We assessed how perceptions and attitudes were affected by individuallevel factors, including demographic and socio-economic factors, and previous experiences with jaguars (i.e. predation history). We expected men and younger people to be more tolerant of jaguars and their conservation (Zinn \& Pierce, 2002; Kleiven et al., 2004; Campbell \& Alvarado, 2011), and a higher level of education to positively affect tolerance of jaguars (Kleiven et al., 2004) and attitudes towards National Park conservation (Infield, 1988; Fiallo \& Jacobson, 1995). We used land and cattle as a proxy for relative wealth and predicted that respondents with larger farms and more cattle would have more positive perceptions of and attitudes towards jaguars (Zimmermann et al., 2005). In addition, we expected more depredation events and monetary losses in Darién National Park than Cerro Hoya National Park because it has more suitable habitat and probably higher densities of jaguars (Fort, 2016).

\section{Study area}

Cerro Hoya National Park $\left(325 \mathrm{~km}^{2}\right)$ is an isolated remnant of tropical rainforest habitat in the south-west of the Azuero Peninsula, between Veraguas and Los Santos provinces
(Fig. 1). There are c. 25 villages and 2,00o inhabitants in the Park, dependent upon crop production, domestic animals (swine and poultry) and cattle ranching (MINAM, 2004). Bordering Colombia, in eastern Panama, Darién National Park $\left(5,790 \mathrm{~km}^{2}\right)$ is a large tract of continuous rainforest habitat and is the country's most extensive National Park. Communities surrounding the Park are dependent upon logging, fishing and livestock, especially cattle (ANCON, 2010).

\section{Methods}

\section{Data collection}

During 2014-2015 we conducted 139 semi-structured, oral interviews with local residents in both study areas to assess their perceptions and attitudes regarding jaguars (Conforti \& Azevedo, 2003; Zimmermann et al., 2005; Campbell \& Alvarado, 2011). Eighty-five interviews were conducted in 23 rural communities around Cerro Hoya National Park and 54 interviews were conducted in five rural communities around Darién National Park (Fig. 1). We surveyed residents most likely to be affected by large carnivores, including landowners and cattle ranchers living in or close to the Parks. Only one adult ( $\geq 18$ years) per household was chosen to be interviewed. Survey methods, questions and interviewers were approved by the Human Subjects Committee at Southern Illinois University (protocol \#13435) before interviews were conducted.

\section{Survey questionnaire}

We developed a structured questionnaire in Spanish, adapted from Zimmermann et al. (2005) and other previously published research on large carnivores (Conforti \& Azevedo, 2003; Campbell \& Alvarado, 2011; Smith et al., 2014). The questionnaire (Supplementary Material) consisted of 32 questions covering three primary subject areas: (1) demographic and behavioural characteristics, (2) knowledge and experience of jaguars, and (3) attitudes towards the jaguar and National Park management. Initially, all respondents were asked to identify jaguars, pumas Puma concolor and ocelots Leopardus pardalis from photographs, to assess if they could correctly distinguish among the three species. Questions 1-7 assessed the respondents' socio-economic status, questions 8-12 assessed their impacts on the Park, and questions $13-15$ assessed their personal experience with jaguars. The question regarding personal encounters with jaguars was excluded from the analysis if the respondent could not correctly identify a jaguar from the photographs.

Questions 16-25 assessed respondents' perceptions and attitudes regarding jaguars and questions 26-30 assessed 


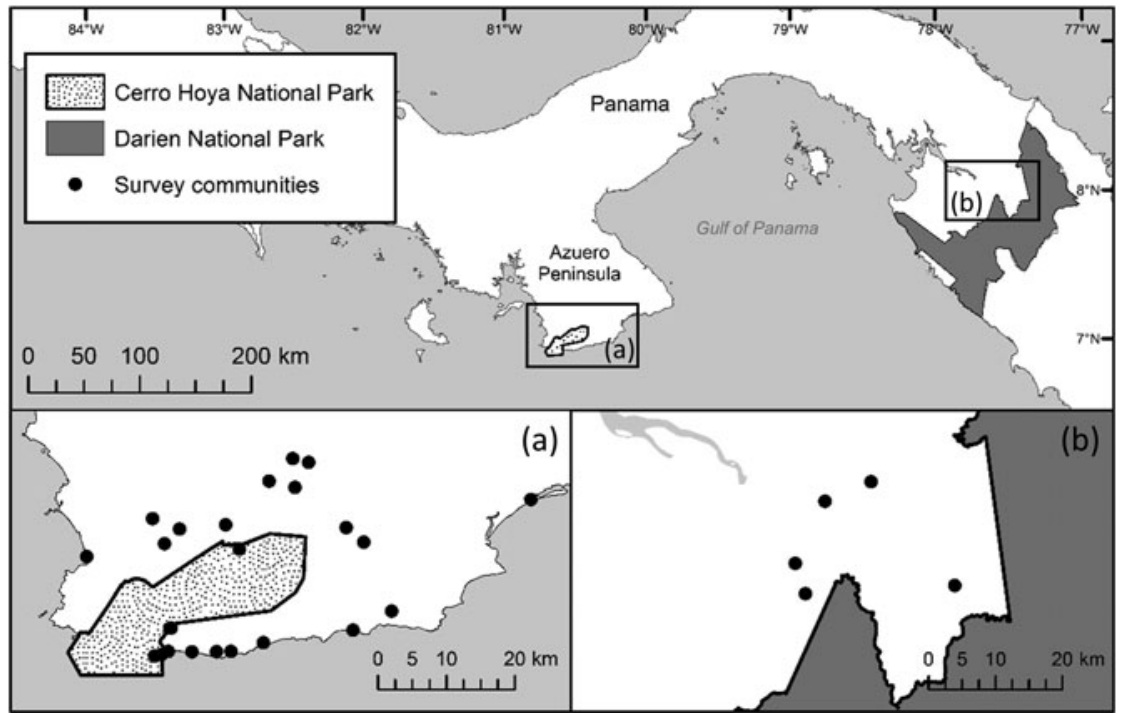

FIG. 1 Communities in and around (a) Cerro Hoya National Park and (b) Darién National Park, Panama, surveyed during 2014-2015 to investigate their attitudes towards jaguars Panthera onca and National Park conservation. their perceptions of their closest National Park, and attitudes towards its management, based on a 5-point Likert scale (1, Strongly disagree; 2, Disagree; 3, Don't know/No opinion; 4, Agree; 5, Strongly agree). Question 31 addressed other wildlife species that were potential threats to their livestock and domestic animals.

\section{Data analysis}

Survey data were analysed using $R v .3 .2$ ( $\alpha=0.05$ throughout; R Development Core Team, 2016). We used independent sample $t$-tests to compare responses between men and women for each survey question. A one-way analysis of variance (ANOVA) was used to compare responses among three or more groups (age, education history, size of ranch, number of cattle) for each survey question. Age was divided into three classes $(18-39,40-59$ and $\geq 60$ years); level of education into five classes (no education, 1st-4th grade (ages 6-9), 5th-8th grade (ages 10-13), some high school-high school graduate, some collegecollege graduate); size of ranch into three classes (small, $<50$; medium, 50-75; and large, $>75 \mathrm{ha}$ ), and number of cattle into three classes (no animals, $1-50$ animals, and $>50$ animals). To assess substantive differences in responses to Likert-scale questions, we considered responses to be significantly different if $\mathrm{P} \leq 0.05$ and mean scores were $\geq 0.5$ points apart (Chavez et al., 2005). Tukey's post-hoc test for pairwise comparisons was used when ANOVA results were significant. We did not pool responses from the two sites for analysis because of observed differences in several demographic variables in addition to strong cultural and socio-economic differences between Latino residents around Cerro Hoya National Park and a mixture of Latino and indigenous Embera-Wounaan communities around Darién National Park (ANCON, 2010; INEC, 2010).

\section{Results}

In both study areas, respondents were aged 22-91 years and the majority of respondents were male (Table 1). In Darién there was a higher percentage of respondents without an education, and a higher percentage with a higher education, than in Cerro Hoya. A greater proportion of respondents in Cerro Hoya owned larger farms and more cattle than in Darién. More respondents in Darién planned to expand their ranch, compared to Cerro Hoya. Nearly a third of respondents in Cerro Hoya admitted to hunting within the Park boundary in the previous year, with $12 \%$ of those hunting on a monthly basis. The collared peccary Pecari tajacu was their most preferred prey. No respondents admitted to hunting within Darién National Park in the previous year, but those that hunted in the past preferred the spotted paca Cuniculus paca.

In both study areas almost all respondents believed that the nature and wildlife of their park was a national treasure and most were in favour of the construction of a road to the park boundary (Table 2). The majority of respondents in Cerro Hoya $(71 \%)$ were worried about the future of the Park and half (51\%) believed it was adequately protected; respondents with a higher education (mean Likert score $=1.30$ \pm SD 0.48) were less likely $\left(F_{4,80}=6.96, \mathrm{P}<0.001\right)$ to agree that the Park was adequately protected (Fig. 2). In Darién, half $(54 \%)$ of respondents were unsure or had no opinion as to whether they were worried about the future of the Park, whereas $35 \%$ of respondents believed the Park was adequately protected; this belief decreased $\left(F_{2,51}=3.18\right.$, $\mathrm{P}=0.049$ ) as the amount of land owned increased (Fig. 3). 
TABLE 1 Summary of demographic characteristics of survey respondents in Cerro Hoya $(\mathrm{n}=85)$ and Darién National Parks $(\mathrm{n}=54)$ in Panama (Fig. 1). Surveys were conducted during 2014-2015.

\begin{tabular}{|c|c|c|}
\hline & Cerro Hoya National Park & Darién National Park \\
\hline \multicolumn{3}{|l|}{ Gender } \\
\hline \% Male (Female) & $76(24)$ & $83(17)$ \\
\hline Mean age (years) & 51 & 48 \\
\hline \multicolumn{3}{|l|}{ Education level } \\
\hline$\%$ with no education & 6 & 11 \\
\hline$\%$ with high school or higher & 22 & 37 \\
\hline \multicolumn{3}{|l|}{ Relative wealth } \\
\hline$\%$ of respondents owning land & 85 & 89 \\
\hline$\%$ of landowners with $>75$ ha & 56 & 6 \\
\hline$\%$ of respondents owning cattle & 62 & 39 \\
\hline$\%$ of cattle owners with $>50$ head & 34 & 24 \\
\hline$\%$ of respondents with plans to expand ranch & 19 & 76 \\
\hline \multicolumn{3}{|l|}{ Hunting } \\
\hline$\%$ of respondents that hunted in previous year & 29 & 0 \\
\hline$\%$ of hunters that hunt at least once per year & 32 & 0 \\
\hline$\%$ of hunters that hunt on a monthly basis & 12 & 0 \\
\hline \multirow[t]{2}{*}{ Preferred species to hunt } & Collared peccary & Spotted paca \\
\hline & Pecari tajacu & Cuniculus paca \\
\hline \multicolumn{3}{|l|}{ Experience of jaguars Panthera onca } \\
\hline No. of respondents that had personally seen a jaguar in their lifetime ${ }^{\star}$ & $23(27 \%)$ & $27(50 \%)$ \\
\hline Depredation events on adult cattle in the previous year & 0 & 22 \\
\hline Depredation events on calves in the previous year & 1 & 11 \\
\hline
\end{tabular}

${ }^{\star}$ Only respondents that correctly identified photographs of felids were included.

In both study areas most respondents believed that more National Parks and wildlife refuges were needed, with a significant positive increase in mean score $\left(F_{4,49}=2.66\right.$, $\mathrm{P}=0.043)$ between respondents that had no education $(\bar{X}=3.50 \pm$ SD 1.64) and those that had reached 1st -4 th grade (4.92 \pm SD 0.29; Fig. 2) in Darién.

A higher proportion of respondents in Darién had personally seen a jaguar in their lifetime compared to Cerro Hoya (Table 1). Six respondents in Darién reported 33 depredation events involving cattle and calves, whereas only one depredation event (involving a calf) was reported in Cerro Hoya. Reported losses for Darién averaged 1.7 cattle per household, constituting 3.6\% of total stockholdings. Most respondents in Cerro Hoya disagreed, and almost all respondents in Darién agreed, that jaguars were a risk to both cattle and humans (Table 2). Despite the high level of perceived risk among respondents in Darién, most respondents in both study areas understood the vital role jaguars played in their ecosystem. In Cerro Hoya, women were more likely to agree than men $\left(t_{27}=2.28, \mathrm{P}=0.031\right.$; Table 3$)$ that they would be happier without jaguars in the area. Furthermore, the number of respondents in Cerro Hoya that agreed they would be happier without jaguars decreased $\left(F_{4,80}=2.67\right.$, $\mathrm{P}=0.038$ ) as level of education increased (Fig. 2). In contrast, most respondents in Darién (76\%) agreed they would be happier without the presence of jaguars.

In both study areas similar proportions of respondents agreed that jaguar populations were decreasing, with men more likely to agree than women in Darién $\left(t_{10}=-2.54\right.$, $\mathrm{P}=0.029$; Table 3). Most respondents in Cerro Hoya (88\%) believed jaguars deserved protection, compared to $31 \%$ of respondents in Darién. Most respondents in Cerro Hoya ( $87 \%)$ believed local authorities should be working to resolve issues of jaguar predation in the area, whereas opinion was divided in Darién (40\% agreed and 46\% disagreed). Almost all respondents in Darién (91\%) indicated they would be open to receiving help on their ranch to mitigate jaguar-human conflict, whereas opinion was divided in Cerro Hoya ( $58 \%$ agreed and $41 \%$ disagreed). However, men in both areas were more open than women to receiving help on their ranches to mitigate jaguar-human conflict (Cerro Hoya: $t_{29}=-2.88, \mathrm{P}=0.007$; Darién: $t_{8}=-2.32, \mathrm{P}=0.047$; Table 3).

Number of cattle and ranch size affected the perceptions and attitudes of respondents in Darién regarding the potential risk posed by jaguars. Belief that jaguars deserve protection decreased $\left(F_{2,51}=3.28, \mathrm{P}=0.050\right)$ between respondents that owned $1-50$ head of cattle $(\bar{X}=4.18 \pm$ SD 0.98) and those that owned $>50$ head $(\bar{X}=3.0 \pm$ SD 0.00). Respondents that owned the most land $(>76$ ha; $\bar{X}=4.0 \pm$ $\mathrm{SD} 1.73)$ were less likely to agree $\left(F_{2,51}=6.03, \mathrm{P}<0.010\right)$ that jaguars were a threat to cattle (Fig. 3). Number of cattle and ranch size did not appear to influence tolerance of jaguars, or attitudes towards the conservation of Cerro Hoya National Park. Age was the only factor that did not influence tolerance of jaguars or attitudes towards park conservation 
TABLE 2 Mean Likert response score ( $1=$ strongly disagree, $5=$ strongly agree) to knowledge and belief statements regarding jaguars and the conservation of Cerro Hoya $(n=85)$ and Darién National Parks $(n=54)$ in Panama (Fig. 1), from a survey conducted during 2014-2015. The statements are adapted from Zimmermann et al. (2005).

\begin{tabular}{llc}
\hline & Mean \pm SD Likert response score \\
\cline { 2 - 3 } Statements & Cerro Hoya National Park & Darién National Park \\
\hline Jaguars are a threat to calves. & $2.66 \pm 1.19$ & $4.91 \pm 0.29$ \\
Jaguars are a threat to adult cattle. & $2.48 \pm 1.17$ & $4.85 \pm 0.49$ \\
Jaguars are a threat to children. & $2.65 \pm 1.29$ & $4.91 \pm 0.29$ \\
Jaguars are a threat to adults. & $2.29 \pm 1.21$ & $4.94 \pm 0.23$ \\
Jaguars are important for the forest and \& other wildlife. & $4.11 \pm 0.83$ & $4.81 \pm 0.52$ \\
Jaguar populations are decreasing. & $3.91 \pm 1.16$ & $4.17 \pm 0.97$ \\
I would be happier if there were no jaguars. & $2.19 \pm 1.25$ & $4.15 \pm 0.92$ \\
Jaguars deserve protection. & $4.14 \pm 0.90$ & $4.02 \pm 0.98$ \\
Jaguar predation on cattle is a problem the local authorities should resolve. & $3.96 \pm 0.84$ & $3.17 \pm 1.49$ \\
I/we would like to receive help at this ranch in solving & $3.04 \pm 1.28$ & $4.80 \pm 0.59$ \\
$\quad$ the jaguar predation issue. & & $4.76 \pm 0.70$ \\
I am in favour of a road being built directly into the park. & $4.00 \pm 1.08$ & $4.85 \pm 0.45$ \\
The nature/wildlife of Cerro Hoya National Park/Darién & $4.34 \pm 0.68$ & $3.15 \pm 1.35$ \\
$\quad$ National Park is a national treasure. & & $3.45 \pm 1.09$ \\
The nature/wildlife of Cerro Hoya National Park/Darién & $2.94 \pm 1.30$ & $4.48 \pm 0.99$ \\
$\quad$ National Park is adequately protected. & &
\end{tabular}

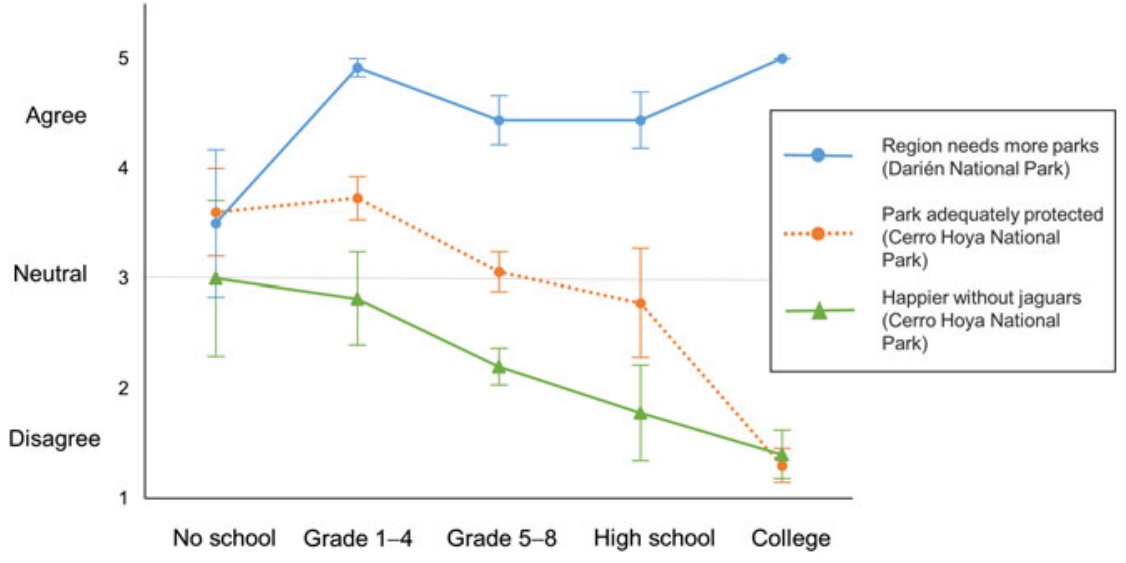

FIG. 2 Mean Likert response scores ( 1 = strongly disagree, $5=$ strongly agree), with standard error bars, to knowledge and belief statements regarding jaguars and conservation of National Parks, according to level of education of respondents in communities in and around Cerro Hoya and Darién National Parks, Panama (Fig. 1), in surveys conducted during 2014-2015. Only significant results are shown. in either study area. Furthermore, when asked if there were any other animals other than jaguars that posed a threat to their livestock, the most common answers in Cerro Hoya were coyotes Canis latrans (68\%) and venomous snakes $(18 \%)$, and in Darién venomous snakes (26\%) and pumas (20\%; Fig. 4).

\section{Discussion}

Our findings indicate there is more human-jaguar conflict in Darién National Park than Cerro Hoya National Park, including direct impacts on people's livelihoods (livestock losses) and direct personal experience (seeing a jaguar). More respondents in Darién had personally seen a jaguar than in Cerro Hoya, and within the previous year 33 depredation events were reported in Darién, compared to only one in Cerro Hoya. It is likely that communities in Darién experienced more issues relating to human-jaguar coexistence because they border much larger, contiguous tracts of forest (i.e. suitable habitat for jaguars; Rabinowitz \& Zeller, 2010) compared to the isolated, fragmented forests of Cerro Hoya (Fort, 2016). Furthermore, the probability of detection of jaguars was higher in Darién (Fort, 2016), probably indicating a higher density of jaguars and therefore a higher probability of human-jaguar interaction.

Levels of jaguar predation on livestock in Darién are similar to those in other communities in Panama and Costa Rica that are located in areas of suitable habitat for 


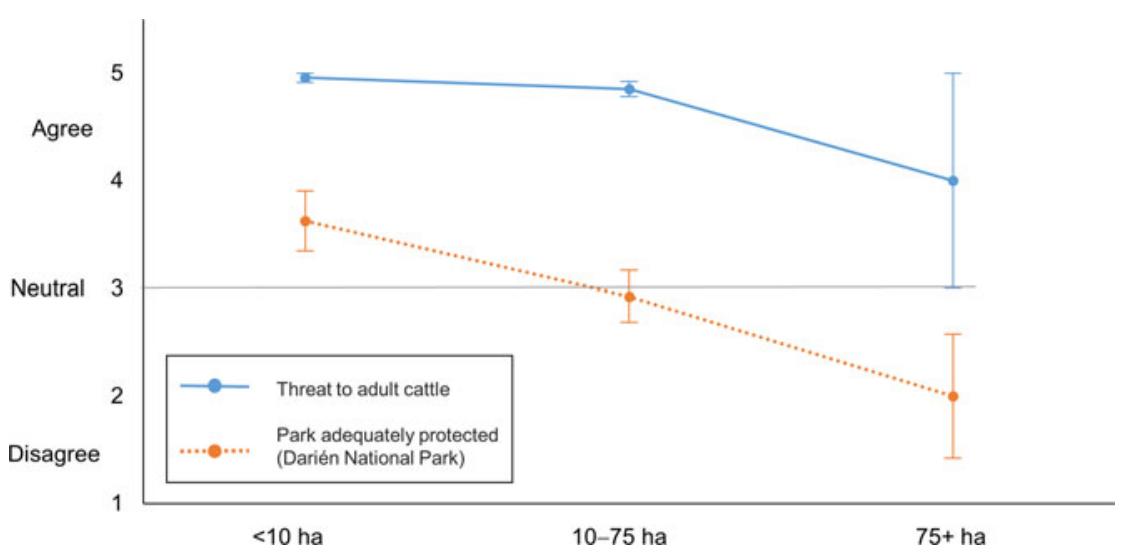

FIG. 3 Mean Likert response score ( 1 = strongly disagree, $5=$ strongly agree), with standard error bars, to knowledge and belief statements regarding jaguars and conservation of National Parks, according to levels of land ownership among respondents in communities in and around Darién National Park, Panama (Fig. 1), during 2014-2015. Only significant results are shown.

TABLE 3 Mean difference (MD) in Likert response scores $(1=$ strongly disagree, $5=$ strongly agree $)$ between female and male respondents to knowledge and belief statements regarding jaguars and conservation in Cerro Hoya and Darién National Parks in Panama (Fig. 1), in surveys conducted during 2014-2015. Statements are adapted from Zimmermann et al. (2005).

\begin{tabular}{|c|c|c|c|c|c|c|c|c|}
\hline \multirow[b]{2}{*}{ Statements } & \multicolumn{4}{|c|}{ Cerro Hoya National Park } & \multicolumn{4}{|c|}{ Darién National Park } \\
\hline & $\mathrm{MD}$ & $t$ & $\mathrm{df}$ & $\mathrm{P}$ & $\mathrm{MD}$ & $t$ & $\mathrm{df}$ & $\mathrm{P}$ \\
\hline Jaguars are a threat to calves. & 0.18 & 0.60 & 32 & 0.550 & 0.16 & -1.03 & 9 & 0.332 \\
\hline Jaguars are a threat to adult cattle. & 0.42 & 1.37 & 31 & 0.181 & 0.09 & -0.54 & 13 & 0.600 \\
\hline Jaguars are a threat to children. & 0.53 & 1.38 & 26 & 0.178 & 0.16 & -1.03 & 9 & 0.332 \\
\hline Jaguars are a threat to adults. & 0.53 & 1.56 & 27 & 0.129 & 0.07 & -0.58 & 9 & 0.577 \\
\hline Jaguars are important for the forest \& other wildlife. & 0.40 & -1.64 & 26 & 0.113 & 0.71 & -2.18 & 8 & 0.060 \\
\hline Jaguar populations are decreasing. & 0.01 & -0.03 & 37 & 0.978 & 1.00 & -2.54 & 10 & $0.029^{*}$ \\
\hline I would be happier if there were no jaguars. & 0.80 & 2.28 & 27 & $0.031^{\star}$ & 0.09 & 0.23 & 10 & 0.823 \\
\hline Jaguars deserve protection. & 0.05 & -0.23 & 31 & 0.819 & 0.42 & -1.16 & 11 & 0.270 \\
\hline Jaguar predation on cattle is a problem the local authorities should resolve. & 0.37 & 1.94 & 37 & 0.060 & 0.20 & -0.38 & 12 & 0.709 \\
\hline $\begin{array}{l}\text { I/we would like to receive help at this ranch in solving the jaguar predation } \\
\text { issue. }\end{array}$ & 0.96 & -2.88 & 29 & $0.007^{*}$ & 0.82 & -2.32 & 8 & $0.047^{\star}$ \\
\hline I am in favour of a road being built directly into the park. & 0.07 & -0.25 & 35 & 0.805 & 0.11 & -0.32 & 9 & 0.756 \\
\hline $\begin{array}{l}\text { The nature/wildlife of Cerro Hoya National Park/Darién National Park is } \\
\text { adequately protected. }\end{array}$ & 0.12 & -0.78 & 41 & 0.437 & 0.22 & -0.92 & 9 & 0.384 \\
\hline $\begin{array}{l}\text { The nature/wildlife of Cerro Hoya National Park/Darién National Park is a } \\
\text { national treasure. }\end{array}$ & 0.01 & 0.03 & 30 & 0.973 & 0.18 & 0.35 & 11 & 0.735 \\
\hline $\begin{array}{l}\text { I am worried about the future of nature/wildlife in Cerro Hoya National } \\
\text { Park/Darién National Park. }\end{array}$ & 0.13 & 0.64 & 45 & 0.525 & 0.62 & 1.68 & 12 & 0.119 \\
\hline The Azuero/Darién Province needs more national parks or wildlife refuges. & 0.11 & -0.46 & 36 & 0.647 & 0.98 & -2.13 & 9 & 0.061 \\
\hline
\end{tabular}

${ }^{*}$ Values were considered significant if $\mathrm{P} \leq 0.05$ and differences in mean scores $(\mathrm{MD})$ were $\geq 0.5$ points apart.

jaguars. In Portobello National Park in northern Panama, Moreno \& Olmos (2008) recorded 309 depredated domestic animals (cattle, horses, sheep and dogs) during 1989-2001, and 22 jaguars were killed by cattle owners during that time. According to a survey in Alto Chagres National Park, Panama, wild felids killed 170 domestic animals during 1985-2008 (Carrión de Samudio \& Samudio, 2012). In Costa Rica a survey conducted among 50 ranching communities during 2007-2009 recorded 81 attacks on livestock by jaguars or pumas (Amit et al., 2013). The percentage of cattle lost to jaguar predation in Darién (c. 3-4\%) is similar to that reported in other studies of large felids (Oli et al., 1994; Patterson et al., 2004; Zimmermann et al., 2005), whereas the level recorded in Cerro Hoya is low.
We used ranch size and number of cattle as a surrogate for relative wealth, as income is positively correlated with positive perceptions of and attitudes towards carnivores (Williams et al., 2002; Dickman et al., 2013). In Darién, landowners with larger farms were less likely to agree that jaguars were a threat to their cattle, and more likely to criticize park management. The positive correlation between ranch size and positive perceptions of jaguars could be explained by more affluence providing a financial buffer against livestock losses (Dickman et al., 2013). However, contrary to our expectation, we found that cattle owners with $>50$ cattle in Darién were less likely to favour the protection of jaguars. One possible explanation for the incongruity between perceptions of landowners and those of 


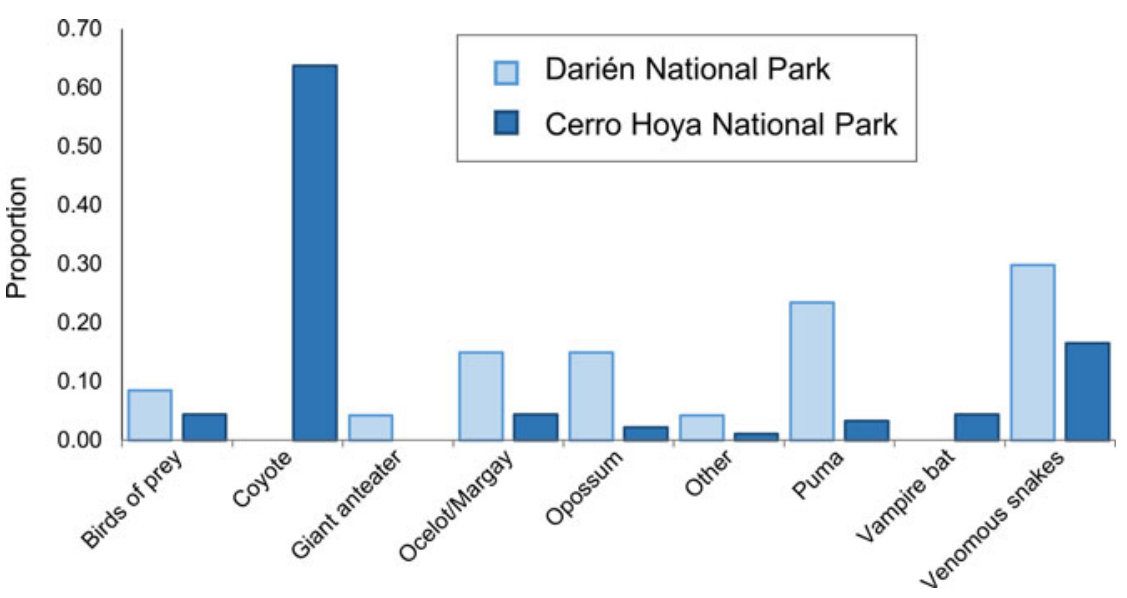

Fig. 4 Proportion of respondents that reported various wildlife species (apart from jaguars) as potential threats to their domestic animals in communities in and around Cerro Hoya and Darién National Parks, Panama (Fig. 1), during 2014-2015. cattle owners is that perceptions may be influenced by the source of income rather than the income itself, and how vulnerable that source would be to threats posed by potentially increasing jaguar populations in the area as a result of protection (Dar et al., 2009; Dickman et al., 2013). In Darién more land was not necessarily synonymous with more cattle; $89 \%$ of respondents owned land but only $39 \%$ owned cattle, with 27 respondents owning land (range 2-70 ha) without cattle. The percentage was greater in Cerro Hoya ( $85 \%$ of respondents owned land and $62 \%$ owned cattle). Although most respondents in Darién perceived jaguars as being a threat to people and cattle in general, ranchers reliant upon revenue from cattle may value jaguar protection less because they have more to lose, whereas landowners without cattle may view jaguar protection more positively because they would not suffer economic losses resulting from livestock predation. We recommend researchers consider using income and income source instead of only ranch size and number of cattle in future surveys in Panama.

Gender appeared to influence perceptions and attitudes in both study areas. In Darién men were more open than women to receiving help on their farms to mitigate impacts from jaguars, and more likely to agree that jaguar populations were decreasing. With more men working outdoors on cattle ranches and crop farms (92.9\% men vs $7.1 \%$ women; INEC, 2010) in Darién Province, they are more likely to be managing farming and cattle operations and more likely have a better understanding of the trends in local wildlife populations. In Cerro Hoya women were more likely than men to agree they would be happier without jaguars, which supports our prediction that women would be less tolerant towards jaguars, and confirms results of previous research (Zinn \& Pierce, 2002; Kleiven et al., 2004; Campbell \& Alvarado, 2011). As women in Cerro Hoya traditionally work in the home (child care and housekeeping), their fear may arise from their protective role as the main caregivers (Zinn \& Pierce, 2002), or from our finding that men may have a better understanding of jaguars because they work in closer proximity to them. Nevertheless, although women in general are more fearful of wild animals than men, they are not necessarily more supportive of their killing (Dickman et al., 2013). In Lithuania 73\% of women perceived local large carnivores as dangerous, compared to $44 \%$ of men, but only $11.5 \%$ of women were in favour of reducing carnivore populations, compared to $16.6 \%$ of men (Balčiauskiene \& Balčiauskas, 2001). In the case of Lithuania and in Cerro Hoya, women's perceptions of jaguars may be linked to cultural expectations and social norms (Dickman et al., 2013).

Education level among respondents in Cerro Hoya had a positive influence on tolerance of jaguars and tended to be associated with increased skepticism that the Park was adequately protected. In Darién, the level of education influenced respondents' receptivity to new parks and wildlife refuges but did not affect their tolerance of jaguars. Our findings in Cerro Hoya support our prediction that the more knowledgeable respondents were about carnivores, the more positively they perceived them (Ericsson \& Heberlein, 2003; Caruso \& Pérez, 2013). In both study areas, education level positively affected attitudes towards conservation of local natural resources, which is supported by previous studies (Infield, 1988; Fiallo \& Jacobson, 1995). Education level may not have affected perceptions of jaguars among respondents in Darién if their values regarding wildlife were established early in life, as these types of values tend to be resilient to change (Bruskotter et al., 2007; Dickman et al., 2013), as discussed below.

Overall, respondents from both study areas had positive perceptions of their respective National Parks, and positive attitudes towards their conservation; however, tolerance of jaguars differed significantly between the study areas. In Darién there was a high perception of risk associated with jaguar attacks on people and cattle, and a low level of acceptance of jaguar presence or their protection. This did not seem to stem from lack of knowledge, as respondents understood the important role jaguars play in their ecosystems, and that their populations are decreasing. In contrast, respondents in Cerro Hoya did not perceive jaguars as a threat 
to people or cattle, were knowledgeable about jaguar ecology and the species' current status, and were tolerant of jaguar presence and protection.

These differences in tolerance are probably attributable to unequal human-jaguar impacts between study areas, and their consequent influence on cultural and societal views; communities in Darién suffer more livestock losses and come into contact with jaguars more often than communities in Cerro Hoya. Over time, such experiences heighten perceptions of risk associated with jaguar presence, perpetuated by the collective experiences of peers, elders, friends, family and local media (Dickman et al., 2013). In contrast, as predation by jaguars is low in Cerro Hoya and the Park's jaguar population is probably small (Fort et al., 2014; Fort, 2016), cultural perceptions of these carnivores may be shifting in a positive direction. Although differences in religion and culture between study areas should not be discounted, we did not assess specific religious and cultural orientations for each respondent. Further investigation is needed to accurately measure these effects on attitudes and perceptions.

Respondents in both study areas shared the perception that their respective National Parks and their resident wildlife were national treasures. These views may be a product of a common social identity (Dickman et al., 2013) among rural Panamanians who tend to depend on the natural resources of neighbouring protected areas and thus have a sense of pride and appreciation of these resources. Similar societallevel influences have been reported for the Iberá Natural Reserve of Corrientes, Argentina, where jaguars have been extirpated. Caruso \& Pérez (2013) found widespread support among rural Corrientinos for the reintroduction of jaguars, which was not affected by age, gender or location, and was affected only slightly by education level and occupation. The authors proposed that attitudes towards jaguar reintroduction were shaped by social identity, as rural Corrientinos view jaguars as a powerful metaphor for their own independent and guerrero (warrior-like) culture.

There were no hunting activities reported in Darién, whereas almost one third of respondents in Cerro Hoya admitted to hunting within the Park limits in the previous year. It is unlikely that no hunting activities occurred in Darién; rather, respondents may have been inhibited to report the truth. In Darién it is not uncommon to see jaguar and ocelot pelts in people's homes, and local people frequently admit to hunting during informal conversations (RM, Yaguará Panamá, pers. comm.). Findings from near Alto Chagres National Park, Panama (Brossard \& Pritz, 2013), in which $47 \%$ of respondents admitted to being regular hunters, with a high frequency of hunting (50\% hunting on a monthly basis), are probably a more accurate portrayal of the hunting situation in Panama. Killing of jaguars in Brazilian protected areas is also underreported, and reporting rates were inversely related to the level of restriction on human use (Carvalho \& Morato, 2013). Although we did not measure level of restriction in Cerro Hoya or Darién National Parks, respondents in Darién may have felt inhibited because of a more frequent presence of environmental officials than in Cerro Hoya, which has not received the same level of protection from government agencies as other National Parks in Panama.

Pumas were the second most commonly reported threat to livestock (after venomous snakes) in Darién, but only 3\% of respondents reported them as being a threat in Cerro Hoya, where communities and ranches are less frequently located near suitable habitat for pumas. The majority of respondents in Cerro Hoya reported coyotes as being a major threat to livestock, whereas there were no reports of such a threat in Darién. Although the distribution of coyotes in Panama is not known precisely, it has expanded as far east as Darién Province (Méndez-Carvajal \& Moreno, 2014) and as far south as the Azuero Peninsula (Fort, 2016), with a significant impact on people reported from Los Santos Province (Bermúdez \& González, 2013). This relatively recent and rapid expansion of coyotes into the Azuero Peninsula could have implications for livestock owners, in addition to introducing novel predation pressures on native prey species that are already isolated and heavily poached.

\section{Conservation implications}

Moreno et al. (2015) predicted that if environmental, social, law enforcement and education conditions in Panama do not change, the killing of jaguars may continue to increase. Furthermore, as 57 respondents from our study plan to expand their ranches in the future, jaguars and their prey are likely to continue losing critical habitat. Our recommendations are pertinent to the findings and suggestions of the National Jaguar Action Plan (MINAM, 2011) and Moreno et al. (2015, 2016). Given the appreciation of Panama's National Parks expressed by respondents in both our study areas, environmental education programmes (Zimmermann et al., 2005; Foster, 2008; Li et al., 2015) should focus on connecting the importance of jaguars to their vital role in maintaining healthy ecosystems within these Parks. In areas where livelihoods have been most affected by livestock losses, and therefore collective experiences over time may negatively influence community perceptions of jaguars, students should be educated at an early age about the importance of carnivores.

Workshops providing training on techniques to mitigate jaguar predation should be initiated by the government or NGOs, and should be tailored to the needs of specific stakeholder groups (Soto-Shoender \& Main, 2013) and incorporate educational materials designed for people with poor literacy skills (Zimmermann et al., 2005; Quigley et al., 2015; Peña-Mondragón et al., 2017). Given that our results 
suggest losses as a result of jaguar predation may be influential in shaping attitudes, economic incentives focusing on improving livestock husbandry practices should be offered in areas where communities suffer the most from the impacts of jaguars on livestock (MINAM, 2011), such as in Darién. The low level of jaguar predation on livestock in Cerro Hoya, despite its isolation and deforestation, may be an indication of low and decreasing jaguar occupancy in the Park (Fort et al., 2014, Fort, 2016). Priorities of wildlife conservation programmes in Panamá should be focused on subpopulations of potentially threatened jaguar populations and the communities nearby, such as those in Cerro Hoya (de la Torre et al., 2017).

\section{Acknowledgements}

This research was funded by Panthera, the McIntire-Stennis Cooperative Forestry Research Program, and GEMAS/Fondo Darién, with additional support from Fundación Natura, and the Department of Forestry and Cooperative Wildlife Research Laboratory at Southern Illinois University. We are grateful to Peace Corps-Panamá and the Azuero Earth Project for providing logistical support and guidance. We also thank the Ministerio de Ambiente (Scientific Permit SE/A-15-15) and Human Subjects Committee at Southern Illinois University (Protocol \#13435) for approval and permits to conduct this research. We are grateful to N. Correa, F. Santamaria, T. Delosrios, E. von Gal, R. Metzel, I. Aust, J. Clay, M. Vega, A. Moreno, J. Wierenga, J. Whelan, Z. Niedzwiecki, E. Sanchez, A. Artavia, J. Ortega, E. Brown, A. Paz, J. Pacheco, T. Contreras, M. Pacheco and the guides of Pijibasal Embera Town for support during field work, and we thank two anonymous reviewers for their insightful input and suggestions.

\section{Author contributions}

JLF designed the study, conducted the fieldwork in Cerro Hoya National Park, analysed the data and wrote the article. CKN supervised the study and advised at all levels of design and data analysis, in addition to helping write and revise the article. ADC advised on certain aspects of the study and provided revisions. RM conducted fieldwork in Darién National Park and provided revisions for the article. NFVM conducted fieldwork in Darién National Park and provided revisions for the article.

\section{References}

Amit, R., Gordillo-Chávez, E.J. \& Bone, R. (2013) Jaguar and puma attacks on livestock in Costa Rica. Human-Wildlife Interactions, $7,77-84$.
ANCON (2010) Plan de Conservación para el Sitio Darién. Asociación Nacional para la Conservación de la Naturaleza, Panamá, [In Spanish]

BalČiauskiene, L. \& Balčiauskas, L. (2001) Threat Perception of Large Carnivores: Are There Sexual Differences? Institute of Ecology, Vilnius, Lithuania.

Bermúdez, S.E.C. \& González, P.D. (2013) Depredación de coyotes (Canis latrans) (Carnivora: Canidae) en animales de producción en Los Santos, Panamá. Mesoamericana, 17, 29-34.

Bowditch, J.L., Buono, A.F. \& Stewart, M.M. (2007) A Primer on Organizational Behavior. Wiley, Hoboken, USA.

Brossard, K. \& Pritz, J.A. (2013) Human-Jaguar Conflict in the Alto Chagres National Park: A Socio-Ecological Study. McGill University, Quebec, Canada.

Bruskotter, J.T., Schmidt, R.H. \& Teel, T.L. (2007) Are attitudes toward wolves changing? A case study in Utah. Biological Conservation, 139, 211-218.

Campbell, M.O. \& Alvarado, M.E.T. (2011) Public perceptions of jaguars Panthera onca, pumas Puma concolor and coyotes Canis latrans in El Salvador. Area, 43, 250-256.

Carrión de Samudio, J. \& Samudio, Jr, R. (2012) Situación del uso de fauna silvestre por las comunidades humanas en el Alto Chagres, Panamá. Mesoamericana, 16, 244. [In Spanish]

Caruso, F. \& Pérez, I.J. (2013) Tourism, local pride, and attitudes towards the reintroduction of a large predator, the jaguar Panthera onca in Corrientes, Argentina. Endangered Species Research, 21, 263-272.

Carvalho, JR, E.A.R. \& Morato, R.G. (2013) Factors affecting big cat hunting in Brazilian protected areas. Tropical Conservation Science, 6, 303-310.

Chavez, A.S., Gese, E.M. \& Krannich, R.S. (2005) Attitudes of rural landowners toward wolves in northwestern Minnesota. Wildlife Society Bulletin, 33, 517-527.

Conforti, V.A. \& Azevedo, F.C.C. (2003) Local perceptions of jaguars (Panthera onca) and pumas (Puma concolor) in the Iguacu National Park area, south Brazil. Biological Conservation, 111, 215-221.

Dar, N.I., Minhas, R.A., Zaman, Q. \& Linkie, M. (2009) Predicting the patterns, perceptions and causes of human-carnivore conflict in and around Machiara National Park, Pakistan. Biological Conservation, 142, 2076-2082.

Davenport, M.A., Nielsen, C.K. \& Mangun, J.C. (2010) Attitudes toward mountain lion management in the Midwest: implications for a potentially recolonizing large predator. Human Dimensions of Wildlife, $15,373-388$.

de la Torre, J.A., González-Maya, J.F., Zarza, H., Ceballos, G. \& Medelín, R.A. (2017) The jaguar's spots are darker than they appear: assessing the global conservation status of the jaguar Panthera onca. Oryx, https://doi.org/10.1017/So030605316001046.

Delibes-Mateos, M. (2014) Negative attitudes towards predators do not necessarily result in their killing. Oryx, 48, 16.

Dickman, A., Marchini, S. \& Manfredo, M. (2013) The human dimension in addressing conflict with large carnivores. In Key Topics in Conservation Biology 2 (eds D.W. Macdonald \& K. J. Willis), pp. 110-126. John Wiley \& Sons, Ltd, Chichester, UK.

Ericsson, G. \& Heberlein, T.A. (2003) Attitudes of hunters, locals, and the general public in Sweden now that the wolves are back. Biological Conservation, 111, 149-159.

Fiallo, E.A. \& JACOBSON, S.K. (1995) Local communities and protected areas: attitudes of rural residents towards conservation and Machalilla National Park, Ecuador. Environmental Conservation, 22, 241-249.

FORT, J.L. (2016) Large carnivore occupancy and human-wildlife conflict in Panamá. MSc thesis. Southern Illinois University, Carbondale, USA. 
Fort, J.L., Nielsen, C.K., Donoso, E., SAmudio, JR, R. \& Duran, G. A. (2014) First camera survey of wild felids in Cerro Hoya National Park, Panama. Cat News, 6o, 36-37.

Foster, R.J. (2008) The ecology of jaguars (Panthera onca) in a human-influenced landscape. PhD thesis. University of Southampton, Southampton, UK.

ineC (Instituto Nacional de Estadística y Censo) (2010) Población de 15 y más años de edad ocupada en la República, por características del empleo, según Provincia, Comarca Indígena, sexo y categoría en la actividad económica: encuesta de Mercado laboral. Instituto Nacional de Estadística y Censo Panamá City, Panamá. Http://www.contraloria.gob.pa/INEC/Publicaciones/Default.aspx [accessed 7 December 2015]. [In Spanish]

INFIELD, M. (1988) Attitudes of a rural community towards conservation and a local conservation area in Natal, South Africa. Biological Conservation, 45, 21-46.

Kleiven, J., Bjerke, T. \& Kaltenborn, B.P. (2004) Factors influencing the social acceptability of large carnivore behaviours. Biodiversity and Conservation, 13, 1647-1658.

LI, C., JiAnG, Z., LI, C., TANG, S., LI, F., Luo, Z. et al. (2015) Livestock depredations and attitudes of local pastoralists toward carnivores in the Qinghai Lake Region, China. Wildlife Biology, 21, 204-212.

Méndez-Carvajal, P.G. \& Moreno, R. (2014) Mammalia, Carnivora, Canidae, Canis latrans (Say, 1823): actual distribution in Panama. Check List, 10, 376-379.

minam (Ministerio de Ambiente) (2004) El plan de manejo del Parque Nacional Cerro Hoya. Ministerio de Ambiente, Las Tablas, Republic of Panamá. [In Spanish]

Minam (Ministerio de Ambiente) (2011) Plan de Acción para la Conservación de los Jaguares en Panamá. Ministerio de Ambiente, Panamá. [In Spanish]

Minam (Ministerio de Ambiente) (2016) Resolución DM-06572016. Ministerio de Ambiente de Panama (MINAM) Listado de las especies de fauna y flora amenazadas de Panama. Gaceta Oficial No. 28187-A.

Moreno, R., Bustamante, A., Mendéz-Carvajal, P. \& Moreno, J. (2016) Jaguares en Panamá: Estado actual y conservacion. In El jaguar en el Siglo XXI: La perspectiva Continental (ed. R. Medellin). CONABIO-Alianza WWF Telcel-Universidad Nacional Autónoma de México, Mexico. [In Spanish]

Moreno, R., Meyer, N., Olmos, M., Hoogesteijn, R. \& Hoogesteijn, A.L. (2015) Causes of jaguar killing in Panama - a long term survey using interviews. Cat News, 62, 40-42.

Moreno, R.S. \& Olmos, M. (2008) Estudio preliminar sobre el problema de la depredación de ganado por jaguares (Panthera onca) y pumas (Puma concolor) en el Parque Nacional Portobelo, provincia de Colón, Panamá. Tecnociencia, 10, 85-98. [In Spanish]

Oli, M.K., Taylor, I.R. \& Rogers, M.E. (1994) Snow leopard Panthera uncia predation of livestock: an assessment of local perceptions in the Annapurna Conservation Area, Nepal. Biological Conservation, 68, 63-68.

Patterson, B.D., Kasiki, S.M., Selempo, E. \& Kays, R.W. (2004) Livestock predation by lions (Panthera leo) and other carnivores on ranches neighboring Tsavo National Parks, Kenya. Biological Conservation, 119, 507-516.

Peña-Mondragón, J.L., Castillo, A., Hoogesteijn, A. \& Martínez-Meyer, E. (2017) Livestock predation by jaguars Panthera onca in south-eastern Mexico: the role of local peoples' practices. Oryx, 51, 254-262.

Porfirio, G., Sarmento, P., Leal, S. \& Fonseca, C. (2016) How is the jaguar Panthera onca perceived by local communities along the Paraguai River in the Brazilian Pantanal? Oryx, 50, 163-168.

Quigley, H., Hoogesteijn, R., Hoogesteijn, A., Foster, R., Payan, E., Corrales, D. et al. (2015) Observations and preliminary testing of jaguar depredation reduction techniques in and between core jaguar populations. Parks, 21, 63-72.

R Development Core Team (2016) R: A Language and Environment for Statistical Computing. R Foundation for Statistical Computing, Vienna, Austria.

Rabinowitz, A. \& Zeller, K.A. (2010) A range-wide model of landscape connectivity and conservation for the jaguar, Panthera onca. Biological Conservation, 143, 939-945.

Smith, J.B., Nielsen, C.K. \& Hellgren, E.C. (2014) Illinois resident attitudes toward recolonizing large carnivores. The Journal of Wildlife Management, 78, 930-943.

Soto-Shoender, J.R. \& Main, M.B. (2013) Differences in stakeholder perceptions of the jaguar Panthera onca and puma Puma concolor in the tropical lowlands of Guatemala. Oryx, 47, 109-112.

Williams, C.K., Ericsson, G. \& Heberlein, T.A. (2002) A quantitative summary of attitudes toward wolves and their reintroduction (1972-2000). Wildlife Society Bulletin, 30, 575-584.

Zimmermann, A., Walpole, M.J. \& Leader-Williams, N. (2005) Cattle ranchers' attitudes to conflicts with jaguar Panthera onca in the Pantanal of Brazil. Oryx, 39, 406-412.

Zinn, H.C. \& PierCe, C.L. (2002) Values, gender, and concern about potentially dangerous wildlife. Environment and Behavior, 34, 239-256.

\section{Biographical sketches}

JESSICA FORT's research interests lie in wildlife conservation and management, in addition to human dimensions of wildlife, particularly in Central America. Clayton Nielsen's research interests include wildlife ecology and management in a variety of landscapes, with a strong focus on habitat and populations, and human dimensions of wildlife. ANDREW CARVER's research interests lie in biodiversity conservation, land-use planning and decision making, and environmental policy and forest economics. RICARDO MORENO's research interests include wildlife ecology and conservation in Panama, and he is currently working to implement the first wild felid conservation programme in Panama. Ninon Meyer's research interests include biodiversity assessment and the ecology of large mammals, with a focus on white-lipped peccaries and Baird's tapirs in Panama and Mexico. 